\title{
THIN FILM TECHNOLOGY USED IN BELL SYSTEM TELECOMMUNICATION CIRCUITS
}

\author{
WALTER WOROBEY \\ Bell Telephone Laboratories, 555 Union Boulevard, Allentown, Pennsylvania 18103
}

\begin{abstract}
This paper describes the thin film technology used for telecommunication circuits in the Bell System. Vacuum deposition and photolithography form the basis for the film processing steps. Nitrogen doped tantalum films are used to form the very stable thin film resistors and capacitors. Laser trimming is used to obtain precision RC active filters. Line widths down to $75 \mu \mathrm{m}$ for conductors and $50 \mu \mathrm{m}$ for resistors are readily achieved in production. The properties of the various components used in thin film integrated circuits are described and examples of completed circuits used in transmission, station, and switching systems are shown. Some key advantages of this technology are low cost due to batch processing techniques, high packing density and high precision of passive components.
\end{abstract}

\section{INTRODUCTION}

Thin film technology used within the Bell System meets the needs of a wide range of applications in transmission, switching, station, and microwave areas. ${ }^{1}$ These needs place increasing demands on the technology and require continuing developments in processing, materials and design. The recent trends in this technology are toward smaller sizes, more complex circuits and improved stability or precision.

Thin film integrated circuits can be divided into three basic categories: conductor circuits, resistor circuits and resistor-capacitor (RC) circuits. Each type can include crossovers to facilitate the interconnection between components and terminals of the hybrid. Also each type, except the RC circuits can be designed as a single level or bi-level circuit. A bilevel design has conductors patterned on both sides of the ceramic which are interconnected by means of metallized via holes. ${ }^{2}$ The via holes are formed in the substrate by laser drilling.

This paper describes the status of thin film technology as it is presently used in production. First it will review the thin film components that are used in hybrid circuits. These components, which include resistors and capacitors, are based on sputtered tantalum and the TiPdAu metallization systems. Performance characteristics and design considerations for current applications will be discussed. Next the processing steps required to make thin film circuits will be described. For most applications beam leaded silicon integrated circuits are thermocompression bonded to the metallization on the ceramic surface. Finally examples of specific thin film circuits will be shown.

\section{THIN FILM COMPONENTS}

\subsection{Conductors}

There are two basic types of metallization systems used for conductors in thin fim circuits. ${ }^{3,4}$ The first type has an end-of-life sheet resistance of $0.05 \mathrm{ohms}$ per square and consists of Ti-Pd-Au. The Ti and Pd are evaporated or sputtered on to the substrate and then gold plated to a thickness of approximately $18 \mathrm{~K} \AA$. The second type c metallization system is used for circuits which require lower conductor resistance. They have an end-of-life sheet resistance of less than $0.005 \mathrm{ohms}$ per square and can consist of either Ti-Pd-Au with $50 \mathrm{~K} \AA$ of $\mathrm{Au}$ or Ti-Pd-Cu-Ni-Au with $40 \mathrm{~K} \AA$ of $\mathrm{Cu}$ and $20 \mathrm{~K} \AA$ of $\mathrm{Au}{ }^{3}$ The latter system is less expensive since it requires less gold. Selective plating is used where possible in order to reduce the amount of gold that must be removed from the substrate surface to define conductor patterns. Typical conductor line widths are $125 \mu \mathrm{m}$ (5 mils), however, line widths down to $75 \mu \mathrm{m}$ ( 3 mils) are used where necessary.

\subsection{Crossovers}

There are three types of crossovers than can be used for thin film circuits. They are the gold beam crossover, ${ }^{5}$ 
the batch bonded crossover ${ }^{6}$ and the thick film crossunder. ${ }^{7}$ The first two are formed by photolithographic techniques and the third type (crossunder) by standard thick film screening and firing techniques. The advantages of the first two are higher crossover density due to smaller line widths (down to $125 \mu \mathrm{m}$ ) and lower capacitance per crossing point. The advantage of the crossunder type is lower cost due to simpler processing and higher yields. In the fabrication of the thick film crossunder the bottom conductor and the glaze insulator are screened and fired using conventional techniques. The top conductor consists of thin film metallization which is photolithographically patterned to form precision lines down to $100 \mu \mathrm{m}$ wide. Hundreds of crossovers can be formed on a thin film circuit with overall yields well above $95 \%$.

\subsection{Resistors}

Thin film resistors consist of reactively sputtered $\mathrm{Ta}_{2} \mathrm{~N}$ having the required sheet resistance. The film is photoetched to form the desired pattern and then pre-aged at $300^{\circ} \mathrm{C}$ for 4 hours or $350^{\circ}$ for 1 hour to form the highly stable component that is required for many precision applications. Typical properties for the thin film $\mathrm{Ta}_{2} \mathrm{~N}$ resistors are shown in Table I. Sheet resistances as high as $300 \Omega / \square$ are standard and used for most applications. Typical TCR for $\mathrm{Ta}_{2} \mathrm{~N}$ is $-90 \mathrm{ppm} /{ }^{\circ} \mathrm{C}$, however, this can be adjusted by varying the sputtering parameters to a value around $-140 \mathrm{ppm} /{ }^{\circ} \mathrm{C}$. This more negative value is desired to match the TCC for $\alpha$-Ta thin film capacitors and thus give a less temperature sensitive RC product. Present technology can provide overall control of the temperature coefficient of the RC product to within $\pm 50 \mathrm{ppm} /{ }^{\circ} \mathrm{C}$ over the temperature
TABLE I

Thin film resistor properties.

\begin{tabular}{ll}
\hline Material & $\mathrm{Ta}_{2} \mathrm{~N}$ \\
Typical sheet resistances & $100 \Omega / \square$ and $300 \Omega / \square$ \\
TCR & $-90 \mathrm{ppm} /{ }^{\circ} \mathrm{C},-140 \mathrm{ppm} /{ }^{\circ} \mathrm{C}$ \\
End of life aging & $+0.1 \%\left(20\right.$ years at $\left.65^{\circ} \mathrm{C}\right)$ \\
Trimming accuracy & $\Delta \mathrm{R} / \mathrm{R}= \pm 0.05 \%$ \\
Line width & $50 \mu \mathrm{m}(2$ mils $)$ \\
\hline
\end{tabular}

range from $-40^{\circ} \mathrm{C}$ to $+85^{\circ} \mathrm{C}$ which includes the operating range of most circuits.

The initial tolerance of resistors is determined by the capability of the laser-trimming process and the control of the short-term stability of the laser trimmed section of the resistor. A typical pattern which allows resistors to be adjusted over a wide range of values is shown in Figure 1. The loops and ladder sections provide the adjustment range. Continuous laser adjustment of the top hats and supplementary tuning sections allows resistors over a few thousand ohms to be trimmed to within 0.05 percent of a specified value.

Long-term resistor aging is determined by the aging of both the untrimmed and laser trimmed parts of a resistor. ${ }^{8}$ Laser trimming within the current path of a resistor tends to degrade the stability of the resistor film and, therefore, should be kept to a minimum. The loop and ladder sections of the resistor are unaffected by laser trimming because the laser-trimmed edge is not in the vicinity of the current path. Accelerated aging studies of typical laser trimmed resistors indicate a 20-year resistance aging of less than 0.1 percent at $65^{\circ} \mathrm{C}$.

Line widths for resistor patterns can be as low as 50 $\mu \mathrm{m}$ ( 2 mils) and still result in acceptable yields using standard photolithographic techniques. This line width

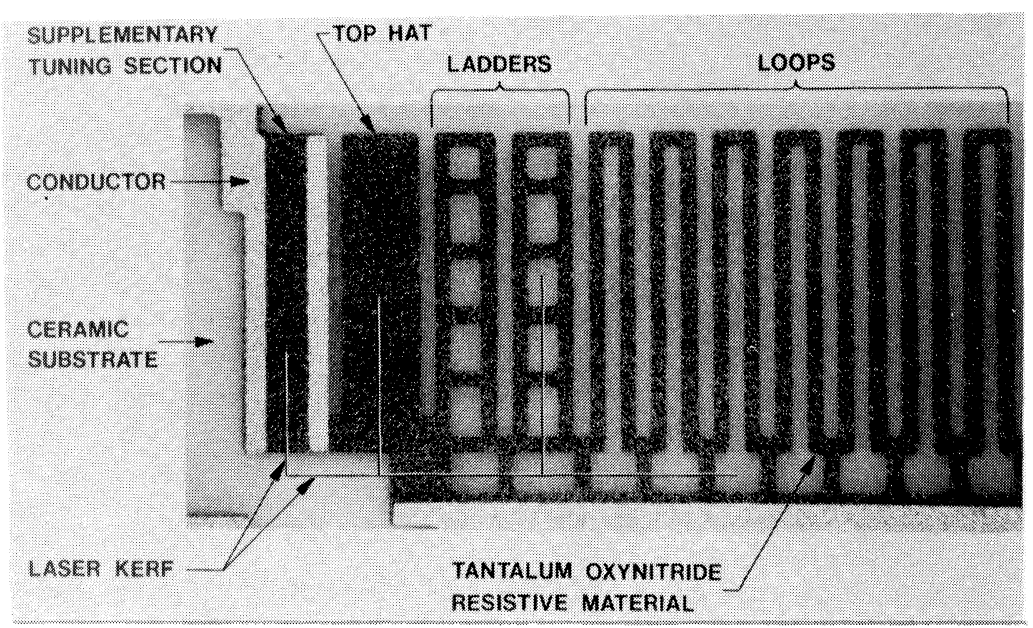

FIGURE 1 Thin film resistor pattern for laser trimming. 
in combination with $300 \Omega / \square$ film results in a resistance density of approximately $6 \mathrm{M} \Omega / \mathrm{cm}^{2}$.

\subsection{Capacitors}

Thin film capacitors are made by anodizing a patterned tantalum film to 190 volts in a 0.01 percent aqueous solution of citric acid and forming an adherent counterelectrode of NiCr-Pd-Au or $\mathrm{Ta}_{2} \mathrm{~N}-\mathrm{Ti}-\mathrm{Pd}-\mathrm{Au}$ on top of the dielectric. Of great importance in fabricating good quality thin film capacitors is the base material from which the dielectric is formed. Sputtered tantalum with approximately 15 atomic percent of nitrogen is the preferred material..$^{9,10}$ This film has a body centered cubic structure and an electrical resistivity of about 100 $\mu \Omega-\mathrm{cm}$. It is often referred to as $\alpha$-Ta because of its structure. Capacitors formed in this manner will typically have the properties shown in Table II after they have been stabilized at $300^{\circ} \mathrm{C}$ for 4 hours. The capacitance density is $64 \mathrm{nF} / \mathrm{cm}^{2}$, the dissipation factor $(\tan \delta)$ at $1 \mathrm{kHz}$ is 0.0015 and the temperature coefficient of capacitance (TCC) is $145 \mathrm{ppm} /{ }^{\circ} \mathrm{C}$. Accelerated aging studies of pre-stabilized thin film capacitors indicate an estimated 20 -year capacitor aging of about -0.15 percent at $65^{\circ} \mathrm{C}$.

The catastrophic failure characteristics of tantalum thin film capacitors depend on the direction of the field in the dielectric. These capacitors can withstand higher dc voltages in the forward direction (i.e. tantalum positive) than in the reverse direction. Acceleration factors are usually calculated from static stress tests over a limited range of stress levels and extrapolations made to determine the working stress conditions for long periods of time. Capacitors with dc working voltages of up to 10 volt forward bias or 0.5 volt reverse bias will have a maximum instantaneous failure rate of below 100 FIT's ( 1 FIT $=1$ failure in $10^{9}$ component hours)

TABLE II

Thin film capacitor properties.

$\begin{array}{ll}\text { Property } & \\ \mathrm{N} \text { concentration } & \sim 15 \text { at } \% \\ \text { Ta crystal structure } & \mathrm{bcc} \\ \text { Ta resistivity } & 100 \mu \Omega \mathrm{cm} \\ \text { Capacitance density }(190 \mathrm{volt} \text { anodization) } & 64 \mathrm{nF} / \mathrm{cm}^{2} \\ \text { Dissipation factor at } 1 \mathrm{kHz} & 0.0015 \\ \text { TCC } & 145 \mathrm{ppm} /{ }^{\circ} \mathrm{C} \\ \text { Capacitor aging }\left(20 \text { years, at } 65^{\circ} \mathrm{C}\right) & -0.15 \% \\ \text { Initial capacitance tolerance } & \pm 5 \text { percent } \\ \text { DC working voltage at } 85^{\circ} \mathrm{C} & 10 \mathrm{~V} \\ \quad \text { forward bias (Ta positive) } & 0.5 \mathrm{~V} \\ \text { reverse bias (Ta negative) } & 7 \mathrm{~V} \mathrm{rms} \\ \text { AC working voltage at } 85^{\circ} \mathrm{C} & \end{array}$

over a 20 -year period at $85^{\circ} \mathrm{C}$. The allowable ac working voltage at $85^{\circ} \mathrm{C}$ is about $7 \mathrm{Vrms}$.

\section{CIRCUIT FABRICATION}

Circuit fabrication can be broken into two main parts; film integrated circuit (FIC) processing and hybrid integrated circuit (HIC) assembly. A typical RC circuit fabrication procedure is shown in Table III. The details

TABLE III

$\mathrm{RC}$ circuit fabrication procedure

\section{FIC process steps}

Selectively glaze ceramic substrate Sputter Ta and oxidize for underlay Sputter $\alpha$-Ta capacitor film

Photoetch capacitor base electrode pattern

Anodize capacitor areas to 190 volts

Sputter $\mathrm{Ta}_{2} \mathrm{~N}$ resistor film

Deposit TiPdAu conductor layer

Photoetch conductor pattern

Photoetch $\mathrm{Ta}_{2} \mathrm{~N}$ resistor pattern

Thermally stabilize R's and C's at $300^{\circ} \mathrm{C}$ for 4 hours

Test capacitors

Laser trim resistors

Hybrid assembly steps

Bond SIC's and attach discrete components

Laser scribe and separate circuits

Attach lead frames

Test circuits

Encapsulate with RTV

Final test

of this fabrication procedure have been described in previous papers. ${ }^{11,12}$ Most of the FIC process steps include vacuum depositions and pattern delineations using standard photolithographic techniques. All of these are batch processing steps in which handling is reduced to a minimum and many circuits are processed simultaneously.

The FIC processing steps are carried out using large ceramic substrates which measure $9.5 \times 11.4 \mathrm{~cm}$. These large substrates contain many individual circuits which are later separated for assembly and testing steps. For example the substrate shown in Figure 2 contains 60 individual $\mathrm{RC}$ filter circuits. This allows more circuits to be processed per hour and thus reduces the cost per circuit to a minimum.

The HIC assembly steps include: attaching components, circuit separation, attaching external leads, encapsulating and testing. The encapsulating material is 


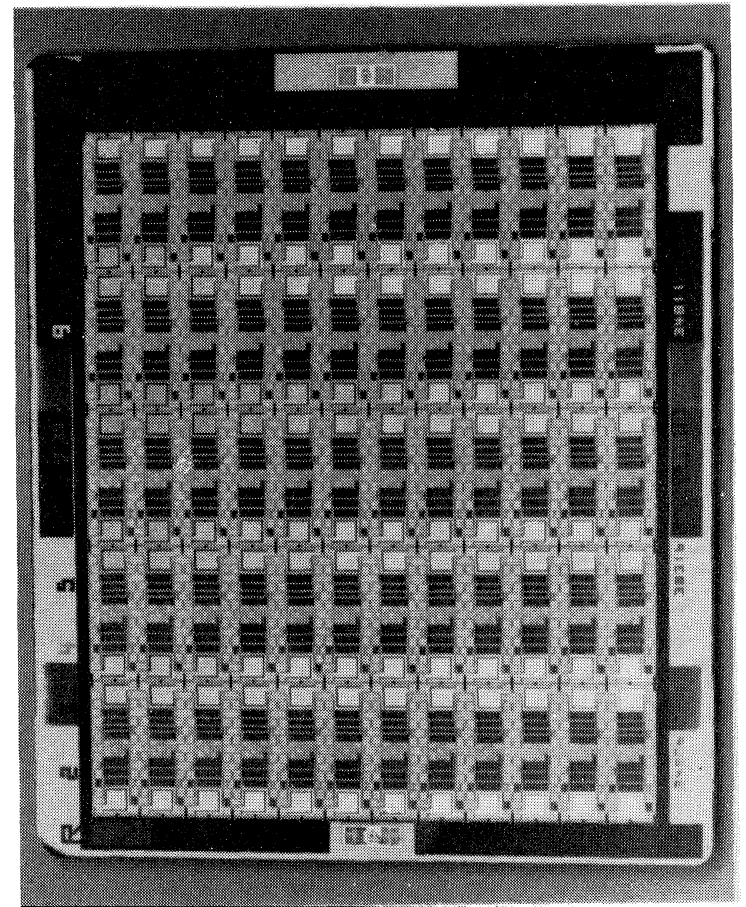

FIGURE 2 Large substrate $(9.4 \times 11 \mathrm{~cm})$ with 60 thin film circuits.

an RTV silicone rubber ${ }^{13}$ which forms a conformal coating over the film integrated circuits and the attached devices.

\section{EXAMPLES OF THIN FILM CIRCUITS}

Examples of completed hybrid integrated circuits prior to encapsulation are shown in Figures 3, 4, 5 and 6. These circuits show the wide range of application of thin film technology within the Bell System. The circuit shown in Figure 3 is an active filter building block called the STAR ( $S$ tandard Tantalum $A$ ctive $R$ esonator) circuit. It is comprised of nine laser-adjustable resistors, two $5100 \mathrm{pF}$ thin-film capacitors and an operational amplifier which is thermal-compression bonded in the centre. It is fabricated on a $1.93 \times 0.66 \mathrm{~cm}$ ceramic substrate and assembled to form a machine-insertable 16-pin dual in-line package (DIP). By laser trimming the resistors to predetermined values and interconnecting the components on the hybrid via the printed wiring board, the STAR circuit can be used to realize a wide variety of low-pass notch, high-pass notch, bandpass, or other filter functions. ${ }^{14,15}$

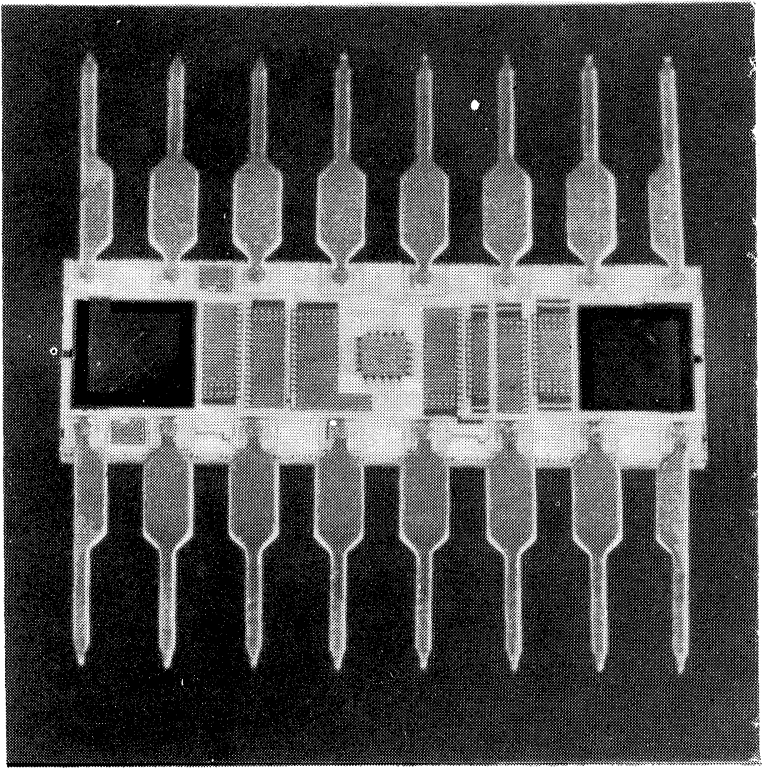

FIGURE 3 Thin film RC circuit used as an active filter building block (STAR).

An example of a custom design $\mathrm{RC}$ circuit used in a transmission system is shown in Figure 4. This is a high stability RC active filter providing a fourth order band elimination filter and a second order bandpass filter. It contains 26 thin film resistors, 6 thin film capacitors and 4 beam leaded SIC's. All of these components with their interconnections are contained on a ceramic substrate which is $3.3 \times 1.4 \mathrm{~cm}$.

An example of a thin film circuit used in station apparatus is shown in Figure 5. This is a line logic hybrid for a PBX system. The substrate which measures $4.1 \times 1.4 \mathrm{~cm}$ contains 4 MSI beam leaded silicon chips as well as thin film conductors and crossovers for interconnections. The external leads are thermocompression bonded on $0.254 \mathrm{~cm}$ centres and are bent to fit on a printed wiring board on rows $1.51 \mathrm{~cm}$ apart.

Finally, Figure 6 shows an example of a thin film circuit used in a switching system. ${ }^{16}$ This 3-port line unit contains 4 large gate array chips having a total of 500 gates. The conductors forming the high density interconnection pattern on the ceramic consist of $75 \mu \mathrm{m}$ ( $3 \mathrm{mil})$ lines and spaces. This hybrid circuit replaced 31 16-pin DIPs which were interconnected on a 6-layer multi-layer printed wiring board. The hybrid measures $4.6 \times 2.0 \mathrm{~cm}$ and contains numerous crossovers to facilitate routing. 


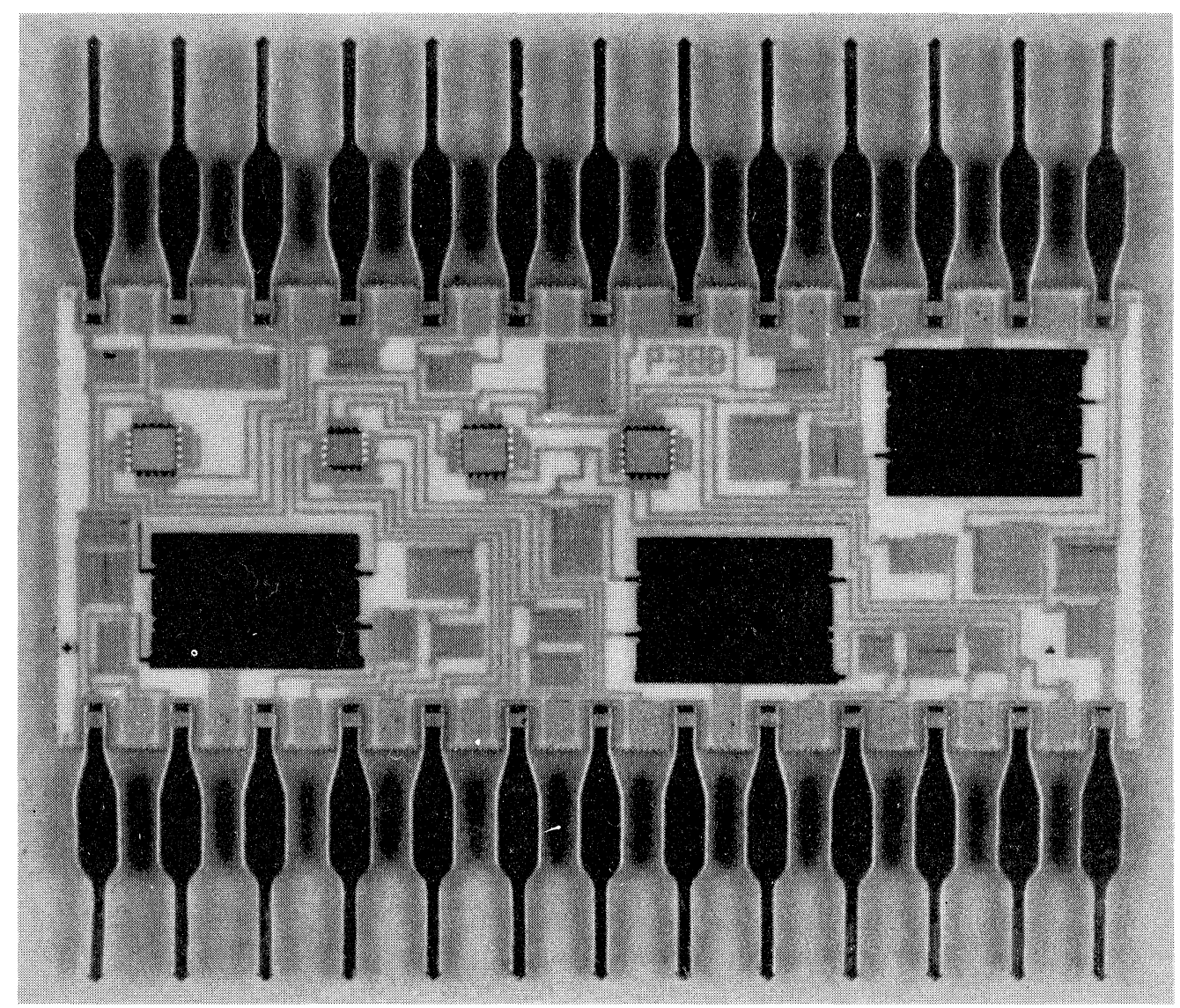

FIGURE 4 Precision RC circuit used in a transmission system.

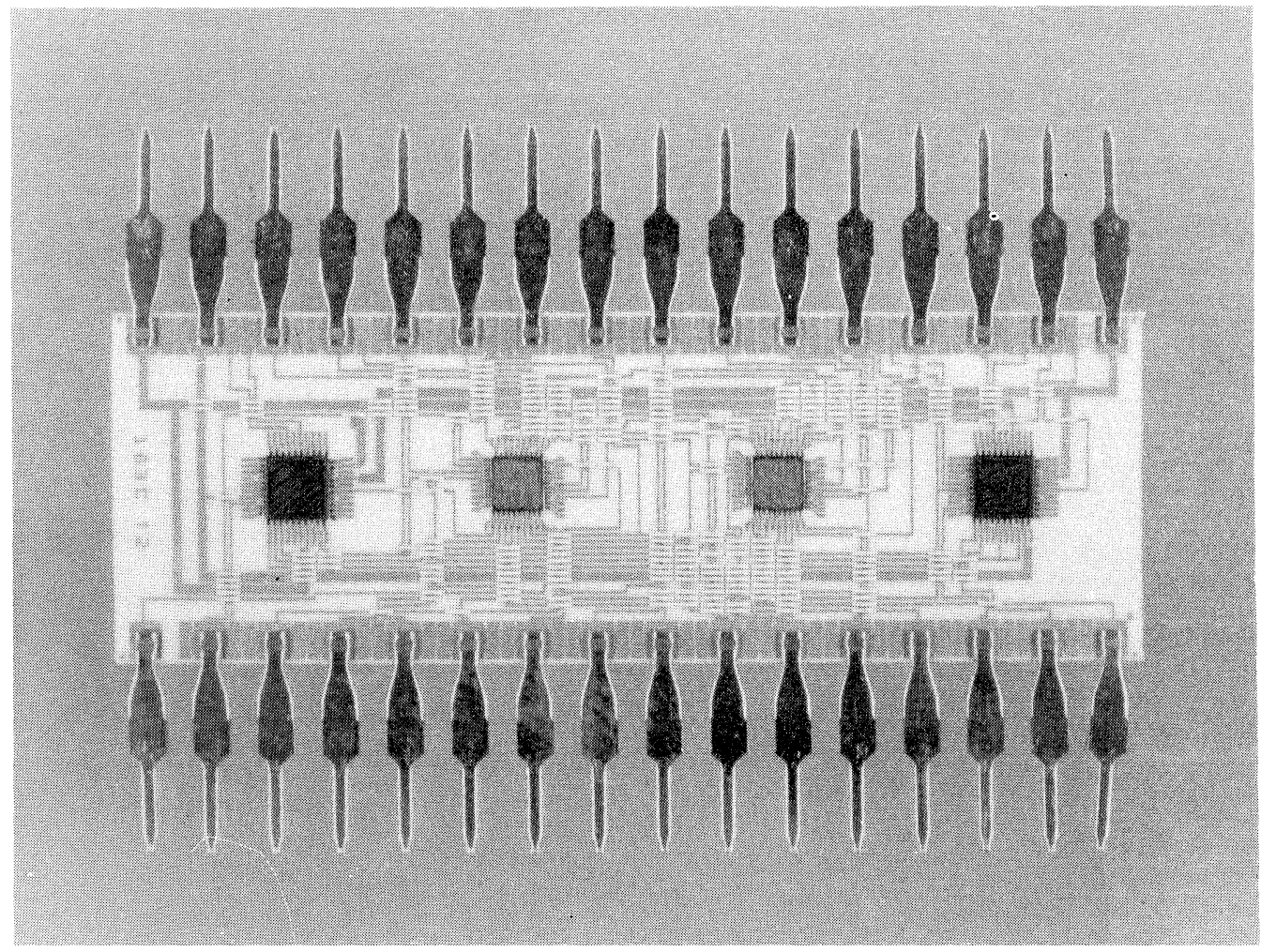

FIGURE 5 Line logic hybrid for PBX system. 


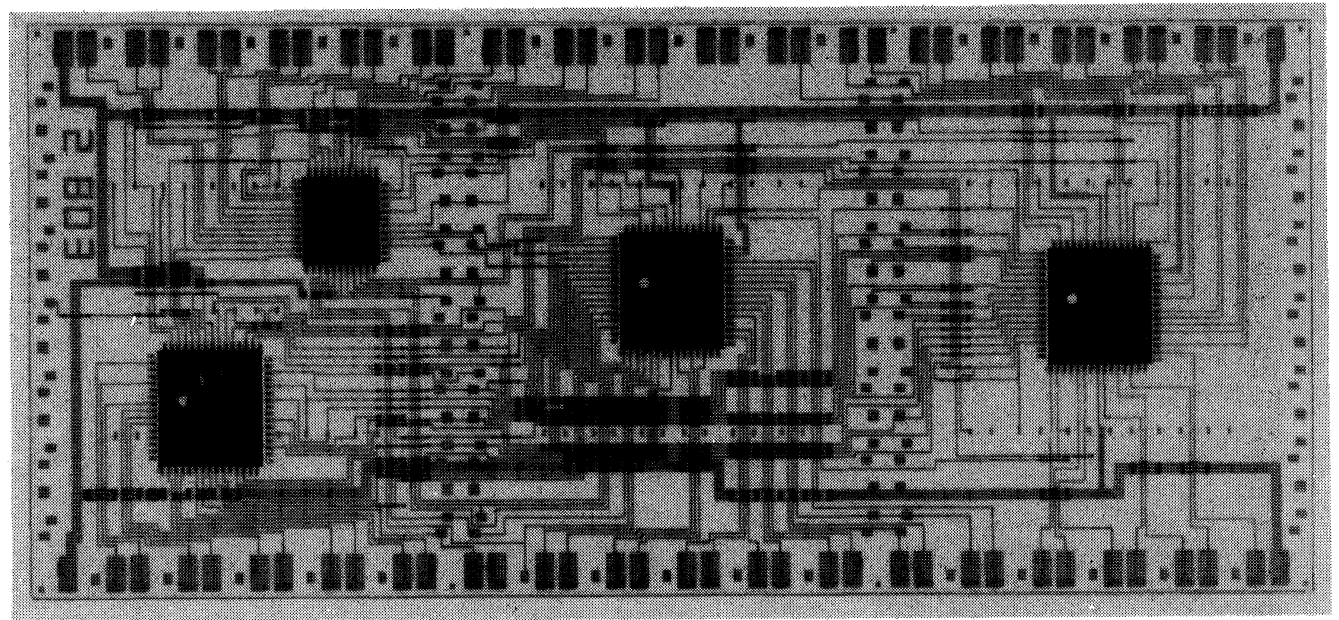

FIGURE $6 \quad 3$ Port line circuit used as a switching peripheral

\section{CONCLUSION}

This paper described the thin film technology which was developed to meet the needs of today's communication systems within the Bell System. The requirements for high precision, highly conductive paths and high packing density for both analog and digital circuits are met with this technology. In addition, the combination of thin film components, high density interconnections and sophisticated silicon integrated circuits offer advantages in miniaturization, low cost and design flexibility for today's system applications. As photolithographic and laser trimming techniques are refined, further reductions in circuit size can be realized for future applications.

\section{REFERENCES}

1. W. H. Orr and T. R. Robillard, "Thin Film Hybrid Integrated Circuits for Communication Systems"-IEEE Trans. Parts, Hybrids \& Packaging Vol. PHP-8, No. 2 p. 51 (June, 1972).

2. T. E. Brady and D. K. Hinderman, "A Bi-Level Thin Film Hybrid Integrated Circuit Containing Crossovers, Resistors and Capacitors," Proc. Elect. Comp. Conf., p. 220 (1973).

3. J. M. Morabito, J. H. Thomas, III, and N. G. Lesh, "Material Characterization of $\mathrm{Ti}-\mathrm{Cu}-\mathrm{Ni}$-Au (TCNA)-A New Low Cost Thin Film Conductor System," IEEE Trans. Parts, Hybrids \& Packaging Vol. PHP-11, No. 4, p. 253 (1975).

4. N. L. Sbar and L. G. Feinstein, "Performance of New Copper Based Metallization Systems in an $85^{\circ} \mathrm{C}, 80$ percent $\mathrm{RH} \mathrm{Cl}_{2}$ Contaminated Environment," IEEE Trans. Parts, Hybrids \& Packaging Vol. PHP-13, No. 3, p. 208 (1977).
5. A. Pfahnl and H. Basseches, "Crossovers for Interconnections on Substrates," Proc. Elect. Comp. Conf., p. 78 (May, 1969).

6. J. A. Burns and D. A. DiLeo, "Batch Bonded Crossovers for Thin Film Circuits"-Solid State Technology (July, 1976).

7. D. H. Klockow, "The Design of Economical Hybrid Integrated Circuits Utilizing Combined Thin and Thick Film Technologies," Proc. Intern. Micro. Symp., p. 139 (1975).

8. G. A. Bulger, "Stability Analysis of Laser Trimmed Thin Film Resistors," IEEE Trans. Parts, Hybrids \& Packaging, Vol. PHP 11, pp. 172-177 (Sept., 1975).

9. M. H. Rottersman, M. J. Bill and D. Gerstenberg, "Ta Film Capacitors with Improved AC Properties," Proc. 27th Elect. Comp. Conf., p. 462 (1977).

10. W. Anders, "Nitrogen-Doped Tantalum Thin Film Capacitors with Improved Temperature Stability"-Thin Solid Film, Vol. 27, p. 135 (1975).

11. O. J. Duff, G. J. Koerckel, E. H. Mayer and W. Worobey, "A High Stability RC Circuit Using High Nitrogen Doped Tantalum," IEEE Trans. Comp. Hybrids \& Manuf. Techn., Vol. CHMT-2, No. 2, p. 221 (June, 1979).

12. O. J. Duff, F. Arcidiacono and G. J. Koerckel, “A Method of Reducing Cost and the Production of High Stability Thin Film RC Networks," 1980 Elect. Comp. Conf., April 28, 1980, San Francisco.

13. D. Jaffe, "Encapsulation of Integrated Circuits Containing Beam Leaded Devices with a Silicone RTV Dispersion," Proc. Elect. Comp. Conf., pp. 376-381 (May, 1976).

14. W. Worobey and J. Rutkiewicz, "Tantalum Thin Film RC Circuit Technology for a Universal Active Filter," IEEE Trans. Parts, Hybrids \& Packaging, Vol. PHP-12, No. 4 p. 276 (1976).

15. J. J. Friend, C. A. Harris and D. Hilberman, "STAR: An Active Biquandratic Filter Section"-IEEE Trans. Circuits and Systems, Vol. CAS-22 (Feb., 1975).

16. C. T. Goddard, "The Role of Hybrids in LSI Systems," IEE Trans. Comp. Hybrids \& Manuf. Techn., Vol. CHMT-2, No. 4, pp. 367-371 (Dec., 1979). 

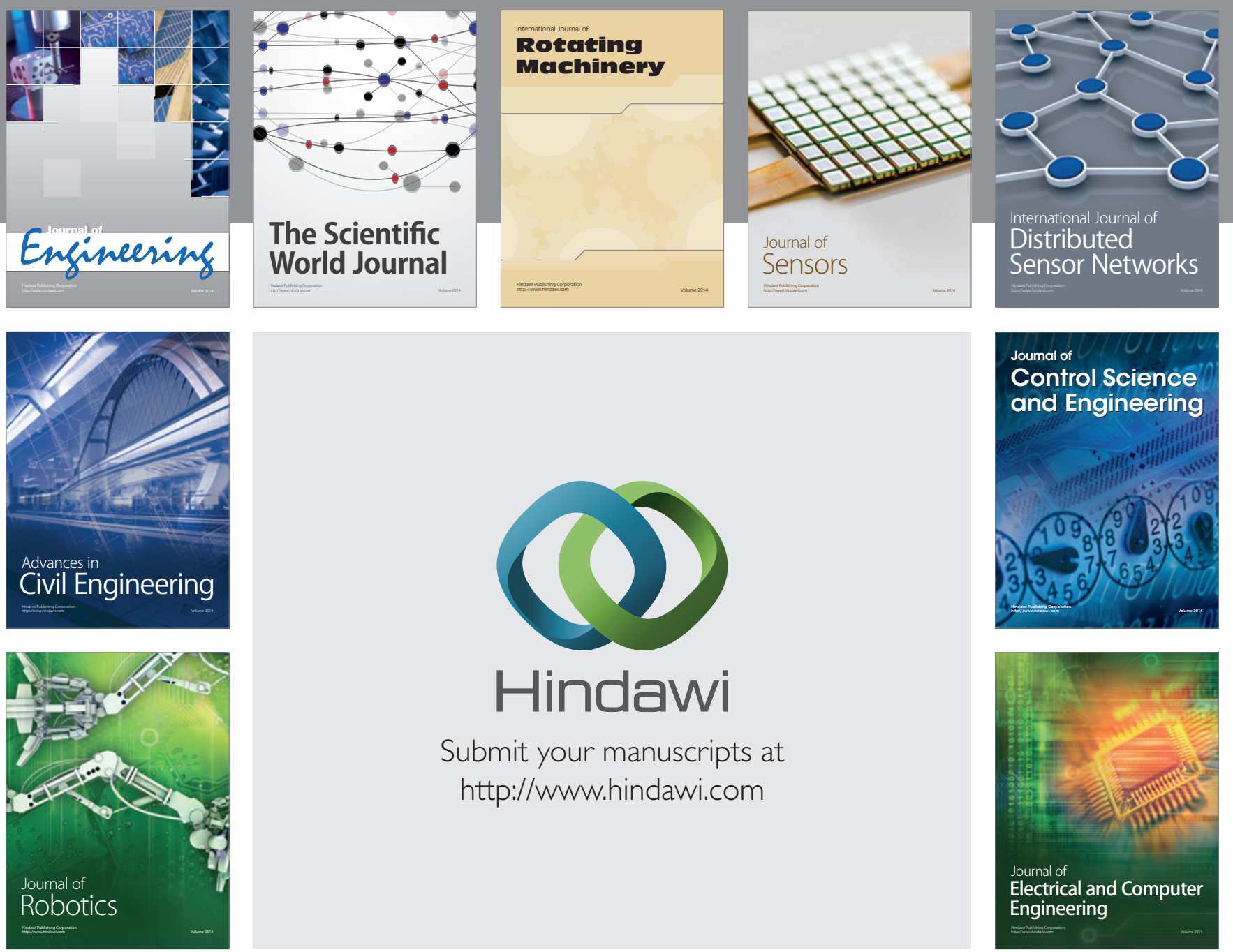

Submit your manuscripts at

http://www.hindawi.com
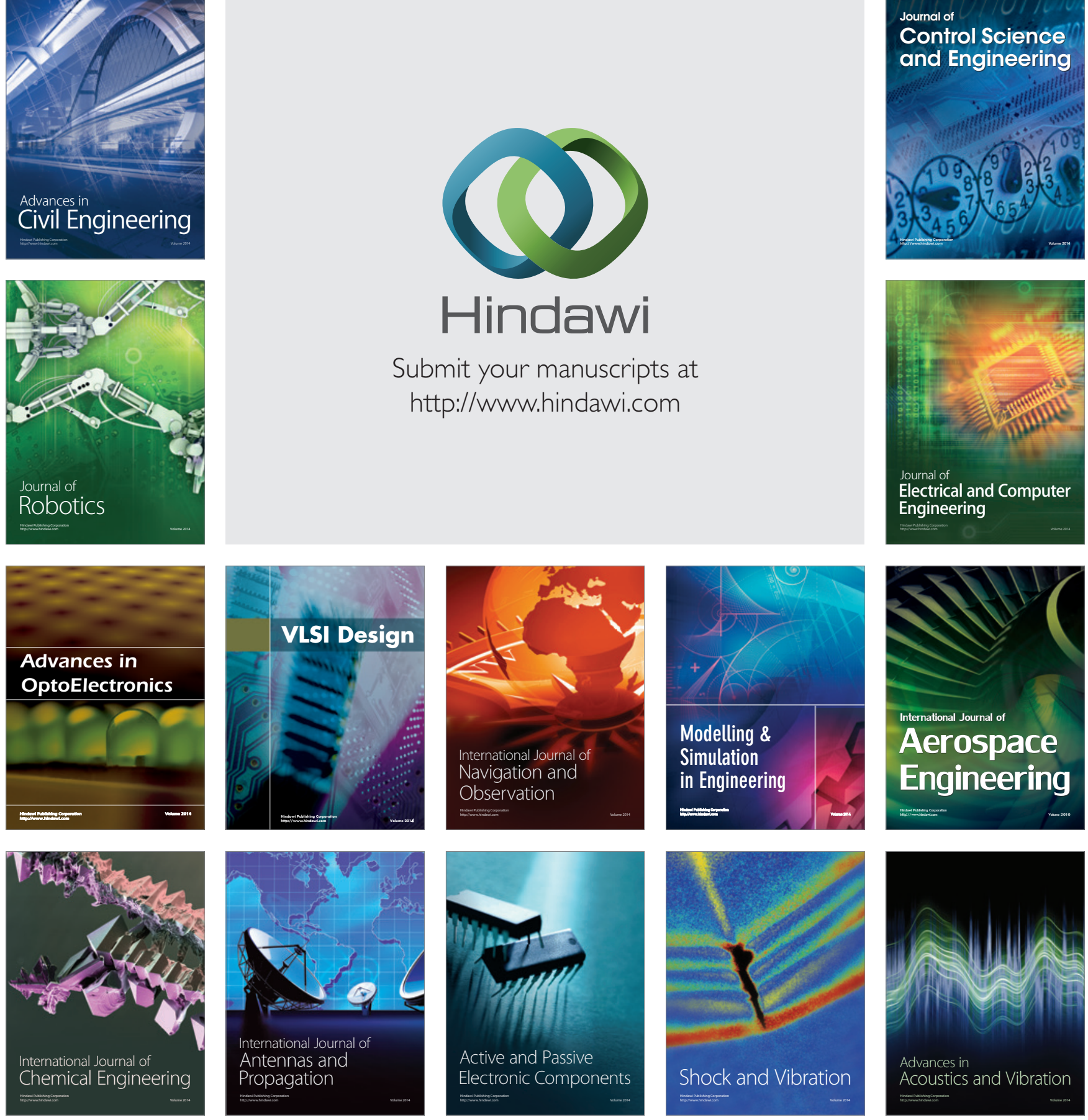